\title{
Assessment of modal beliefs about using an electronic supermarket
}

\author{
Peter Roberts, Ron Henderson \& Debra Rickwood \\ Centre for Applied Psychology \\ University of Canberra \\ ACT 2616 \\ Australia \\ petrob@ozemail.com.au
}

\begin{abstract}
36 users of a prototype electronic supermarket answered open ended questions regarding beliefs, social pressures and perceived control relating to the service. Results indicated mainly positive salient beliefs about the service, perceived behavioral control dominated by concerns about the system and the importance of social pressures on usage. Analysis revealed that convenience, time saving and money saving were the primary positive beliefs with lack of sensory cues the primary negative belief. The implications of the study for the use of predictive theoretical models are discussed.
\end{abstract}

\section{KEY WORDS}

Electronic supermarket, Theory of Planned Behavior, Technology Acceptance Model.

\section{Introduction}

The aim of the study was to identify modal salient beliefs, primary sources of social pressure and modal perceived behavioral controls arising from the use of the electronic supermarket service. Results are to be used in the application of the Theory of Planned Behavior as a predictor of the use of the service and to ascertain whether the Technology Acceptance Model has validity outside workplace and educational environments.

\section{METHOD}

\subsection{Sample}

A total of 36 users of a prototype electronic supermarket participated. Users were mainly working adults, with access to a computer and modem, predominantly female (24), and identified themselves as the main shopper in the household.

\subsection{Measures}

Using the procedures outlined by Ajzen and Fishbein, subjects were asked to respond to list advantages and disadvantages of the service, significant persons who approved or disapproved of their usage, as well as inhibiting and facilitating factors which could affect their use of the service. Subjects were also asked to list any other matters relating to the service they considered important. No indication was given to subjects as to the number of factors required under each category. 
In developing a predictive model, it would be normal practice to elicit salient beliefs from a sample before they commenced the behavior. Because of the highly innovative nature of the activity, it would have been very difficult for subjects to conceptualise the activity to a level where sufficient salient beliefs could be generated for analysis and therefore experienced subjects were used.

\subsection{Procedure}

19 users answered the seven open ended questions as part of a larger self-report questionnaire and 15 answered by telephone interview.

\section{Results}

In total 212 salient beliefs, 70 sources of social pressure and 90 behavioral control factors were listed. These factors were grouped into 22 categories. Using a cut off of $80 \%$ for categorised factors on each construct, the following have been identified as the modal beliefs.

\begin{tabular}{|lr|}
\hline & \\
Salient beliefs & $28.7 \%$ \\
convenience & $17.0 \%$ \\
negative system attributes & $10.4 \%$ \\
lack of sensory cues & $7.1 \%$ \\
saving time & $6.6 \%$ \\
saving money & $6.1 \%$ \\
positive system attributes & $4.7 \%$ \\
enjoyment & \\
& \\
Subjective norms & $24.3 \%$ \\
friends & $18.6 \%$ \\
work colleagues & $17.1 \%$ \\
family & $5.7 \%$ \\
spouse & $5.7 \%$ \\
"anti-computer" people & $2.9 \%$ \\
traditional grocery retailers & \\
& \\
Perceived behavioural control factors \\
specific assisting system factors & $23.3 \%$ \\
specific system difficulties & $16.7 \%$ \\
costs & $15.6 \%$ \\
availability of equipment & $14.4 \%$ \\
difficulties with technology & $11.1 \%$ \\
\hline
\end{tabular}

\section{Discussion}

The study of the attitude-behavior relation arising from the introduction of innovative information technology has been examined largely in the workplace and educational environments. Much of this research has been conducted using the Technology Acceptance Model (TAM), a derivative of the Theory of Reasoned Action (TRA). Studies comparing the TAM with the TRA support the finding that the primary antecedent beliefs about predicting the use of innovative information technology are the perceived usefulness of the system to the user and the system's ease of use. Also this research indicates that perceived social pressures to use or not to use the system (subjective norms) are not an important factor in decisions on use in workplace and educational environments.

The electronic supermarket is an application of information technology outside those environments and is a quite radical departure from the socially significant activity from physically visiting shops. This study supports the necessity to revisit the fundamentals of the TRA in that it indicates that the salient beliefs go beyond those presumed by the TAM. Convenience was nominated as the most important factor which equates to usefulness and system attributes (both positive and negative), equating to ease-of-use, were together the next ranked factor. Additional factors (sensory cues, saving money and enjoyment) are outside the scope of the TAM, but rated as important by the users. The importance of subjective norms was highlighted by the high response rate to those factors, indicating a social perspective of electronic shopping.

The subsequent addition of perceived behavioral control factors to the TRA to form the Theory of Planned Behavior is a recognition that the attitudebehavior relation exists is not confined to purely volitional decisions. Further research will be needed to determine whether subjects view electronic shopping as a purely volitional activity or is significantly affected by the control factors nominated. 